\title{
QUALIDADE NO ATENDIMENTO: UM ESTUDO REALIZADO NA SECRETARIA MUNICIPAL DE EDUCAÇÃO DE PONTES E LACERDA - MT
}

\author{
Alessandra Cristina Rubio¹; Enerson Alves ${ }^{2}$; Thiago Silva Guimarães ${ }^{3}$. \\ ${ }^{1}$ Doutoranda em Ciências Contábeis e Administração, FUCAPE Business School (FUCAPE), \\ Vitória-ES. \\ ${ }^{2}$ Bacharel em Administração Pública, Modalidade a distância-EAD, Universidade do Estado de \\ Mato Grosso (UNEMAT). \\ ${ }^{3}$ Doutorando em Ciências Contábeis e Administração, FUCAPE Business School (FUCAPE), \\ Vitória-ES.
}

DOI: 10.47094/ICONACON.2021.7

\begin{abstract}
RESUMO
Este artigo teve como objetivo, verificar o nível de satisfação dos servidores da Escola Municipal Professora Rosilei Pereira dos Santos, quanto ao atendimento ofertado pela Secretaria Municipal de Educação de Pontes e Lacerda - MT, com o intuito de averiguar como os funcionários da secretaria de educação, atendem os servidores da supracitada escola, e a qualidade desse atendimento, e explicar como ocorre o processo de comunicação entre os servidores de ambas as instituições. Para esse fim, utilizou-se métodos qualitativos com pesquisa bibliográfica e estudo de campo, com a aplicação de um questionário contendo 9 (nove) questões objetivas 1 (uma) subjetiva, direcionadas a 25 (vinte e cinco) servidores da escola municipal Professora Rosilei Pereira dos Santos. E após análise, concluiuse que a maioria dos usuários avalia o atendimento como bom, e demonstram estar satisfeitos com a agilidade e a qualidade do serviço ofertado.
\end{abstract}

PALAVRAS-CHAVE: Qualidade no atendimento. Motivação. Comunicação.

ÁREA TEMÁTICA: Outras.

\section{INTRODUÇÃO}

$\mathrm{O}$ atendimento no setor público ou privado, tem suas ações efetivadas por meio do trabalho humano, que precisam satisfazer as expectativas dos usuários, através de serviços com boa qualidade. Os servidores possuem a obrigatoriedade de estarem devidamente qualificados e preparados para realizar os procedimentos cabíveis ao solicitado, como também apresentar conduta coadunável às expectativas dos usuários do serviço público (DE PAULA; NOGUEIRA, 2016). 
Para um bom desenvolvimento o atendimento nas organizações públicas, deve ser realizado com qualidade e eficiência, com isso a pesquisa busca saber se os usuários da Secretaria Municipal de Educação de Pontes e Lacerda- MT estão satisfeitos com o atendimento prestado pelo órgão.

Na concepção de Deming, (1993, p.56) a "qualidade é tudo aquilo que melhora o produto do ponto de vista do cliente", portanto o produto ou serviço oferecido pode ser projetado e se preciso modificado sempre direcionando o foco a qualidade é a satisfação do usuário.

O atendimento tem uma parcela importante no processo de satisfação dos usuários, pois cada pessoa espera ser atendida de forma que suas questões sejam sanadas de maneira rápida e eficiente. Dessa forma, esta pesquisa procura responder a seguintes questões: Os servidores da Escola Municipal Professora Rosilei Pereira dos Santos estão satisfeitos com o atendimento prestado pela Secretaria Municipal de Educação de Pontes e Lacerda - MT?

Para alcançar este objetivo geral, foram elencados os seguintes objetivos específicos: Identificar o nível de satisfação dos servidores da Escola Municipal Professora Rosilei Pereira dos Santos, quanto ao atendimento ofertado pela Secretaria Municipal de Educação de Pontes e Lacerda - MT; Descrever como os servidores da secretaria de educação, atendem os servidores da supracitada escola e; explicar como ocorre o processo de comunicação entre os servidores de ambas as instituições.

\section{METODOLOGIA}

Para atingir os objetivos propostos pela pesquisa adotaremos em primeiro momento um levantamento bibliográfico, o qual proporcionara melhor enfoque com o tema, que de acordo com Marconi e Lakatos (2003, p.183) a pesquisa bibliográfica "abrange toda a bibliografia já tornada pública em relação ao tema de estudo, desde publicações avulsas, boletins, jornais, revistas, livros, pesquisa, $[. .$.$] até meios de comunicação orais".$

O objetivo desta pesquisa é verificar, se os servidores da Escola Municipal Professora Rosilei Pereira dos Santos, estão satisfeitos com o atendimento prestado pela Secretaria Municipal de Educação de Pontes e Lacerda.

O estudo de campo realizou-se na Escola Municipal Professora Rosilei Pereira dos Santos que está localizada no município de Pontes e Lacerda - Mato Grosso. Os dados foram coletados, através da aplicação de questionários, contendo nove (9) questões fechadas e uma (1) aberta, de acordo com Pereira Filho (2013) podemos destacar como vantagens na aplicação de questionários a possibilidade de abranger um maior número de sujeitos e restringir às questões a exatamente àquilo que desejamos saber. Para os devidos preenchimentos dos questionários contamos com a colaboração dos servidores da referida instituição. 
Os questionários foram aplicados para um total de vinte e cinco (25) funcionários, sendo vinte (20) professores, dois (2) coordenadores, dois (2) secretários e um (1) diretor, sendo todos, servidores da referida escola. Para preservar a imagem dos entrevistados, estes não foram identificados e responderam o questionário, de forma individual, sem o auxílio do pesquisador, provendo assim maior liberdade aos entrevistados, para que a pesquisa seja eficaz. Todos os participantes responderam o questionário, totalizando $100 \%$ de adesão.

\section{RESULTADOS E DISCUSSÕES}

A Secretária Municipal de Educação está localizada do município de Pontes E Lacerda - Mato Grosso. Atualmente atende a onze (11) unidades escolares sendo cinco (5) Centros Educacionais Infantil e seis (6) escolas de Ensino Fundamental, prestando o suporte para essas unidades, sendo na estrutura física e financeira, atendendo as escolas com transporte escolar, uma equipe com nutricionista para a merenda escolar e uma equipe pedagógica para dar suporte aos coordenadores e professores destas unidades escolares.

O desenvolvimento da pesquisa ocorreu na Escola Municipal Professora Rosilei Pereira dos Santos através da aplicação do questionário, contendo nove (9) questões objetivas e uma (1) subjetiva, objetivando, analisar a qualidade do atendimento prestado pela Secretaria Municipal de Educação, o nível de satisfação dos usuários, e identificar como ocorre o processo de comunicação, entre os servidores da escola e os funcionários da secretaria de educação. A escola funciona nos períodos matutino e vespertino, ofertando o nível fundamental, apenas os anos iniciais do $1^{\circ}$ ao $5^{\circ}$ ano, foi escolhida por ser considerada uma escola de médio porte, com número significativo de funcionários para a pesquisa.

Gráfico 1 - Nível de satisfação do atendimento

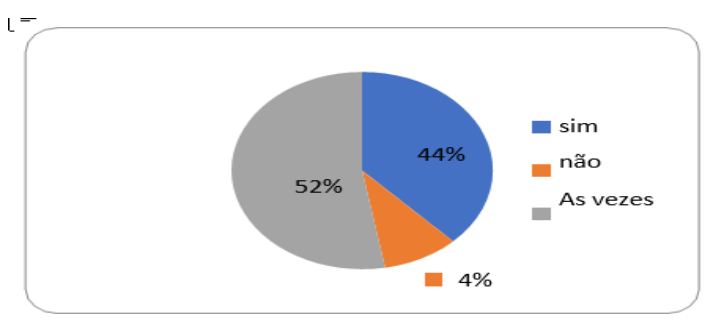

Fonte: Elaborado pelo autor, 2021.

Neste gráfico vemos que, $52 \%$ consideram que, às vezes o atendimento satisfaz suas necessidades, 44\% responderam sim e 4\% acham que não satisfaz. De acordo com Dantas (2010 apud kotler, 1998, p.55) a satisfação é “o sentimento de prazer ou de desapontamento resultante da comparação de desempenho esperado pelo produto (ou resultado) em relação às expectativas da pessoa". 
Gráfico 2 - Agilidade no atendimento

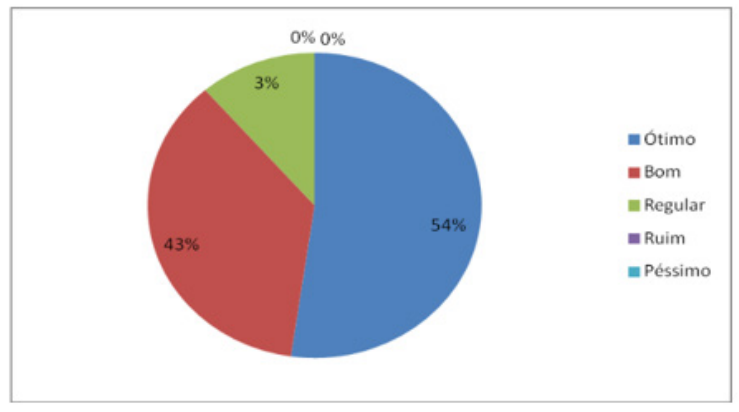

Fonte: Elaborado pelo autor, 2021.

Os dados observados no quarto gráfico revelam, que 76\% dos participantes julgam que a agilidade no atendimento como bom, $20 \%$ consideram ótimo e $4 \%$ acham regular. A rapidez no atendimento é um fator importante, pois diminui o tempo nas filas de espera e o usuário sente que o atendente está realmente preocupado com ele e que deseja solucionar seu problema o quanto antes, com isso o usuário tem uma experiência positiva e um bom nível de satisfação.

Tabela 1 - Pontos positivos e negativos do atendimento

\begin{tabular}{|c|c|}
\hline Pontos Positivos & Pontos negativos \\
\hline $\begin{array}{l}\text { Fornecimento de material didático;Atendem as escolas; } \\
\text { Boa postura dos servidores ao atender;Objetividade e } \\
\text { conhecimento das informações; } \\
\text { Rapidez no atendimento; Disposição em } \\
\text { ajudar; Receptivos e companheiro;Empenho } \\
\text { na educação; Trabalho em grupo; Abertos ao } \\
\text { diálogo; } \\
\text { Liberdade em avaliar o órgão. }\end{array}$ & $\begin{array}{l}\text { Falta de informação sobre o } \\
\text { sistemaescolar; } \\
\text { O espaço físico do } \\
\text { prédio;Burocracia; } \\
\text { Falta de objetividade das } \\
\text { informações;Poucos funcionários; } \\
\text { Demora de resposta que depende de } \\
\text { outrosetor ou órgão; } \\
\text { Melhores recursos de trabalho; }\end{array}$ \\
\hline
\end{tabular}

Fonte: Elaborado pelo autor, 2021.

Observa-se que são muitos os pontos levantados pelos participantes, entretanto alguns estão em ambos os lados, quer dizer, é difícil atender a todos de forma que suas necessidades sejam supridas.

\section{CONSIDERAÇÕES FINAIS}

Através dos resultados da pesquisa realizada na Escola Municipal Professora Rosilei Pereira dos Santos sobre o atendimento ofertado pela Secretaria Municipal de Educação, observou-se que a maioria dos usuários considera o atendimento bom, mas o órgão deve continuar investindo no atendimento para suprir as necessidades de seus usuários. Ao atender, o comportamento dos atendentes é imprescindível para obter um bom atendimento, através desta pesquisa podemos averiguar que a 
maior parte dos usuários julga que o atendente tem uma postura que os agradam ao atender. De acordo com as respostas dos usuários internos, às vezes a Secretaria satisfaz as suas necessidades. A comunicação é importante para que o atendente corresponda à expectativa do usuário, dessa forma pode se considerar a comunicação entre na Secretaria Municipal de Educação e os usuários internos, como boa.

Esta pesquisa possibilitou aos usuários, opinarem em relação à qualidade do atendimento prestado pela Secretaria Municipal de Educação e de posse dos resultados os servidores podem observar a sua postura quanto atendente e buscarem treinamento nessa área assim se aperfeiçoarem.

\section{REFERENCIAS}

DANTAS, Edmundo Brandão. Atendimento ao público nas organizações: quando o marketing de serviços mostra a cara. 3. ed. Brasília: Editora SENAC DF, 2010. 175p.

DEMING, W. Edwards. Qualidade: a revolução da administração. Rio de janeiro: Marques saraiva 1990.

DE PAULA, Vilson Vieira; NOGUEIRA, Giulia de Mendonça. A importância da área de gestão de pessoas, para o sucesso da organização. XII Congresso Nacional de Excelência em g e s tã o . 2016. Disponível em: <http://www.inovarse.org/sites/default/files/T16_047.pdf>. Acesso em: 16 de jan. de 2021

MARCONI, Marina de Andrade; LAKATOS, Eva Maria. Técnicas de pesquisa: planejamento e execução de pesquisas, amostragens e técnicas de pesquisa, elaboração, análise e interpretação de dados. 7 ed. São Paulo: Atlas, 2008. 277 p. 